\title{
Seleksi Pegawai Kontrak Menjadi Pegawai Tetap Dengan Metode Profile Matching
}

\author{
Khairul $^{1}$, Suherman ${ }^{2}$ \\ ${ }^{12}$ Program Studi Sistem Komputer, Fakultas Sains dan Teknologi, Universitas \\ Pembangunan Panca Budi \\ e-mail: ${ }^{1}$ khairul@dosen.pancabudi.ac.id, ${ }^{2}$ suherman@dosen.pancabudi.ac.id
}

\begin{abstract}
Labor is the most important factor in the management of an enterprise. Quality of labor greatly determines the progress and development of the company .. At present the company generally apply the contract system in the recruitment of employees. So the process of recruitment of contract employees is very critical to get a professional workforce and quality. Contract workers who are considered competent and make a large contribution deserve to be appointed permanent employees.

The problem of recruitment of contract employees to permanent employees can be completed by Profile Matching method. Profile Matching method is a method that matches the ideal profile with the profile of each contract employee. The smaller the value of the difference between the ideal profile and the profile of each employee (gap), the greater the chances of contract employees being appointed permanent employees.

Profile Matching method can provide the best recommendations in the recruitment process of contract employees into permanent employees.
\end{abstract}

Keywords : Contract Employee, Labor, Permanent Employee, Profile Matching, Recruitment.

\begin{abstract}
Abstrak
Tenaga kerja adalah faktor terpenting dalam manajemen suatu perusahaan. Kualitas tenaga kerja sangat menentukan kemajuan dan perkembangan perusahaan.. Pada saat ini perusahaan secara umum menerapkan sistem kontrak dalam rekrutmen pegawai. Sehingga proses rekrutmen pegawai kontrak merupakan hal yang sangat kritis untuk mendapatkan tenaga kerja yang profesional dan berkualitas. Pegawai kontrak yang dinilai kompeten dan memberikan kontribusi besar layak untuk diangkat menjadi pegawai tetap.

Masalah rekrutmen pegawai kontrak menjadi pegawai tetap dapat diselesaikan dengan metode Profile Matching. Metode Profile Matching adalah metode yang mencocokkan profil ideal dengan profil setiap pegawai kontrak. Semakin kecil nilai selisih antara profil ideal dengan profil setiap pegawai (gap), maka semakin besar peluang pegawai kontrak diangkat menjadi pegawai tetap.
\end{abstract}

Metode Profile Matching dapat memberikan rekomendasi terbaik dalam proses rekrutmen pegawai kontrak menjadi pegawai tetap.

Kata kunci : Pegawai Kontrak, Pegawai Tetap, Rekrutmen, Profile Matching, Tenaga Kerja.

\section{PENDAHULUAN}

Dalam kegiatan manajemen usaha atau bisnis yang dijalankan perusahaan, tenaga kerja merupakan salah satu faktor penting. Tenaga kerja ikut menentukan tercapainya tujuan dan proses kegiatan usaha untuk mencapai keberhasilan yang telah ditetapkan oleh suatu perusahaan. Tanpa adanya tenaga kerja yang berkualitas proses kerja tidak akan maksimal dan akan mengganggu stabilitas sebuah perusahaan. 
PT.NS BlueScope Lysaght Medan adalah salah satu perusahaan milik asing yang bergerak dalam bidang konstruksi dan merupakan produsen atap serta rangka baja. Perusahaan ini merupakan cabang dari PT NS BlueScope Lysaght yang beroperasi di kota Medan. Dalam proses rekrutmen pegawainya perusahaan ini menerapkan sistem kontrak dan outsourcing yang dibagi menjadi beberapa divisi dam mengacu pada UU No. 13 Tahun 2003 tentang ketenagakerjaan. PT.NS BlueScope Lysaght Medan telah memiliki standar baku dalam proses rekrutmen pegawainya, namun dalam penerapannya masih mengalami kendala karena prosesnya masih dikerjakan secara manual dan analisanya belum menggunakan metode yang jelas sehingga membutuhkan waktu yang lama [1].

Salah satu metode yang dapat digunakan dalam memecahkan masalah ini adalah Profile Matching. Menurut Asmita dan Sodhi (2013), Profile Matching memberikan rekomendasi untuk terhubung dengan orang lain dengan mencocokkan entitas profil seseorang pada media sosial. Menurut Yarlagadda dan Naresh (2015), privasi seseorang pada sosial media dapat ditingkatkan menggunakan prinsip Profile Matching. Sedangkan menurut Ramanjulu dan Babu (2014), Profile Matching diterapkan untuk keamanan perangkat portabel jaringan publik [2][4][6].

Beberapa penelitian yang pernah dilakukan untuk membantu memecahkan masalah berkaitan dengan Profile Matching. Menurut Nina Sherly (2013), metode Profile Matching dapat diterapkan dalam mendukung keputusan dalam memberikan bonus bagi karyawan [5]. Sedangkan berdasarkan penelitian Asfan Muqtadir dan Irwan Purdianto (2013), seleksi kenaikan jabatan karyawan dapat menggunakan metode Profile Matching [3].

\section{METODOLOGI PENELITIAN}

Sebelum menerapkan metode Profile Matching diperlukan beberapa analisa kebutuhan data dan metodologi penelitian yang tepat agar masalah dapat diselesaikan dengan metode yang digunakan.

\subsection{Analisa Data Pegawai}

Data pegawai kontrak yang akan diolah adalah pegawai yang bekerja pada divisi factory yaitu sebanyak 8 pegawai yang telah menjalani kerja dengan masa kontrak selama 2 tahun.

Tabel 1. Data Pegawai Kontrak

\begin{tabular}{|c|l|c|l|c|}
\hline NO & $\begin{array}{c}\text { Nama } \\
\text { Pegawai }\end{array}$ & $\begin{array}{c}\text { Id } \\
\text { pegawai }\end{array}$ & Divisi & Posisi \\
\hline 1 & $\begin{array}{l}\text { Benny } \\
\text { Wijaya }\end{array}$ & TOF1 & Factory & Manufacturer \\
\hline 2 & $\begin{array}{l}\text { Dalvin } \\
\text { Ginting }\end{array}$ & TOF2 & Factory & $\begin{array}{c}\text { Technical } \\
\text { Logistic }\end{array}$ \\
\hline 3 & $\begin{array}{l}\text { Dedi } \\
\text { Harmoko }\end{array}$ & TOF3 & Factory & $\begin{array}{c}\text { Technical } \\
\text { Operator }\end{array}$ \\
\hline 4 & $\begin{array}{l}\text { Dedy } \\
5\end{array}$ & Tofyan & Factory & $\begin{array}{c}\text { Technical } \\
\text { Logistic }\end{array}$ \\
\hline 6 & Himinas & TOF6 & Factory & $\begin{array}{c}\text { Technical } \\
\text { Logistic }\end{array}$ \\
\hline
\end{tabular}




\begin{tabular}{|l|l|l|l|c|} 
& & & & Operator \\
\hline 7 & Idris purba & TOF7 & Factory & Manufacturer \\
\hline 8 & Saimun & TOF8 & Factory & Manufacturer \\
\hline
\end{tabular}

\subsection{Analisa Data Pegawai}

Berikut data kriteria yang akan digunakan untuk penilaian pegawai :

Tabel 2. Data Kriteria Penilaian

\begin{tabular}{|c|c|c|c|c|c|c|c|}
\hline Kriteria & Bobot & $\begin{array}{c}\text { Sub } \\
\text { Kriteria }\end{array}$ & $\begin{array}{c}\text { Kode } \\
\text { Kriteria }\end{array}$ & $\begin{array}{l}\text { Core } \\
\text { Factor } \\
(\mathrm{CF})\end{array}$ & $\begin{array}{l}\text { Secondary } \\
\text { Factor } \\
\text { (SF) }\end{array}$ & $\begin{array}{c}\% \\
\mathrm{CF}\end{array}$ & $\begin{array}{l}\% \\
\text { SF }\end{array}$ \\
\hline \multirow{5}{*}{$\begin{array}{c}\text { Internal } \\
\text { Skill } \\
\text { (IS) }\end{array}$} & \multirow{5}{*}{$50 \%$} & Safety & IS1 & $\sqrt{ }$ & & \multirow{5}{*}{$60 \%$} & \multirow{5}{*}{$40 \%$} \\
\hline & & Disiplin & IS2 & $\sqrt{ }$ & & & \\
\hline & & $5 \mathrm{~S}$ & IS3 & $\sqrt{ }$ & & & \\
\hline & & Quality & IS4 & & $\sqrt{ }$ & & \\
\hline & & Productivity & IS5 & & $\sqrt{ }$ & & \\
\hline \multirow{8}{*}{$\begin{array}{c}\text { Technical } \\
\text { Skill }\end{array}$} & \multirow{8}{*}{$40 \%$} & Mesin RF & TS6 & $\sqrt{ }$ & & \multirow{8}{*}{$80 \%$} & \multirow{8}{*}{$20 \%$} \\
\hline & & $\begin{array}{l}\text { Mesin } \\
\text { Folder }\end{array}$ & TS7 & $\sqrt{ }$ & & & \\
\hline & & Mesin Trust & TS8 & $\sqrt{ }$ & & & \\
\hline & & $\begin{array}{l}\text { Mesin } \\
\text { Crimping }\end{array}$ & TS9 & $\sqrt{ }$ & & & \\
\hline & & Compressor & TS10 & & $\sqrt{ }$ & & \\
\hline & & Crane & TS11 & & $\sqrt{ }$ & & \\
\hline & & Uppender & TS12 & & $\sqrt{ }$ & & \\
\hline & & Forklift & TS13 & & $\sqrt{ }$ & & \\
\hline \multirow{3}{*}{$\begin{array}{c}\text { Utilities } \\
\text { Skill } \\
\text { (US) }\end{array}$} & \multirow{3}{*}{$10 \%$} & $\begin{array}{l}\text { Trouble } \\
\text { Shooting 'n } \\
\text { Maintenance }\end{array}$ & US14 & $\sqrt{ }$ & & \multirow{3}{*}{$70 \%$} & \multirow{3}{*}{$30 \%$} \\
\hline & & $\begin{array}{l}\text { ROA 'n } \\
\text { Yield }\end{array}$ & US15 & $\sqrt{ }$ & & & \\
\hline & & $\begin{array}{l}\text { Training/ } \\
\text { Seminar/ } \\
\text { Workshop }\end{array}$ & US16 & & $\sqrt{ }$ & & \\
\hline
\end{tabular}

\subsection{Analisa Parameter Nilai Sub Kriteria}

Pengisian nilai sub kriteria penilaian pegawai kontrak mengacu pada standar baku yang diterapkan pada perusahaan. Untuk melihat dari parameter nilai yang akan dijadikan panduan setiap penilaian dapat dilihat pada tabel berikut: 
Tabel 3. Parameter Nilai Sub Kriteria

\begin{tabular}{|c|c|c|}
\hline No. & Rating Penilaian & Nilai \\
\hline 1 & Belum Terbukti & 1 \\
\hline 2 & Masih Lemah & 2 \\
\hline 3 & Cukup & 3 \\
\hline 4 & Kompeten & 4 \\
\hline 5 & Sangat Memuaskan & 5 \\
\hline
\end{tabular}

\subsection{Analisa Pemetaan Gap}

Pembahasan yang dimaksudkan pada pemetaan gap adalah untuk mengetahui perbedaan nilai sub kriteria pada setiap orang pegawai kontrak dengan kriteria ideal yang ditetapkan oleh perusahaan sesuai dengan aspek penilaian.

Tabel 4. Bobot Nilai Gap Pegawai

\begin{tabular}{|c|c|c|l|}
\hline No & Selisih & $\begin{array}{c}\text { Bobot } \\
\text { Nilai }\end{array}$ & \multicolumn{1}{|c|}{ Keterangan } \\
\hline 1 & 0 & 5 & $\begin{array}{l}\text { Tidak ada selisih (Kompetensi sesuai dengan yang } \\
\text { dibutuhkan) }\end{array}$ \\
\hline 2 & 1 & 4,5 & Kompetensi pegawai kelebihan 1 tingkat/ level \\
\hline 3 & -1 & 4 & Kompetensi pegawai kekurangan 1 tingkat/ level \\
\hline 4 & 2 & 3,5 & Kompetensi pegawai kelebihan 2 tingkat/ level \\
\hline 5 & -2 & 3 & Kompetensi pegawai kekurangan 2 tingkat/ level \\
\hline 6 & 3 & 2,5 & Kompetensi pegawai kelebihan 3 tingkat/ level \\
\hline 7 & -3 & 2 & Kompetensi pegawai kekurangan 3 tingkat/ level \\
\hline 8 & 4 & 1.5 & Kompetensi pegawai kelebihan 4 tingkat/ level \\
\hline 9 & -4 & 1 & Kompetensi pegawai kekurangan 4 tingkat/ level \\
\hline
\end{tabular}

\subsection{Implementasi Metode Profile Matching}

Tahapan selanjutnya ketika kebutuhan data telah terpenuhi, maka langkah selanjutnya adalah menyesuaikan algoritma Profile Matching dengan data yang telah ada agar hasil penerapannya akurat dan sesuai dengan kebutuhan perusahaaan. Beberapa Tahapan algoritma Profile Matching untuk mengolah data rekrutmen pegawai kontrak menjadi pegawai tetap adalah:

1. Mempersiapkan data sub kriteria hasil penilaian kinerja pegawai kontrak.

2. Menentukan sub kriteria ideal yang dibutuhkan perusahaan.

3. Menentukan gap masing-masing sub kriteria. 
4. Memberi bobot dari masing-masing gap, kriteria dan persentase Core Factor serta Secondary Factor.

5. Kelompokkan sub kriteria hasil penilaian kinerja pegawai kontrak menjadi Core Factor dan Secondary Factor. Lalu hitung nilai $C F$ dan $S F$.

6. Hitung seluruh nilai akhir dengan penjumlahan persentase kriteria yang telah dihitung nilai total $C F$ dan $S F$ pada sub kriteria.

7. Setelah nilai akhir telah didapatkan, maka selanjutnya lakukan pengurutan rangking nilai akhir masing-masing pegawai kontrak.

8. Analisa hasil penerapan metode Profile Matching untuk memberikan rekomendasi status baru pegawai kontrak.

\section{HASIL DAN PEMBAHASAN}

\subsection{Input Nilai Sub Kriteria Pegawai Kontrak dan Sub Kriteria Ideal}

Pegawai yang sudah dikontrak oleh perusahaan akan dinilai kinerjanya sesuai job desc dan tugas yang diberikan oleh perusahaan. Job desc dan tugas yang diberikan akan menjadi sub kriteria penilaian. Yaitu sub kriteria internal skill, technical skill, dan advance skill yang diubah menjadi variabel IS, TS, dan AS.

Tabel 5. Nilai Sub Kriteria Variabel Internal Skill, Technical Skill, dan Variabel Skill

\begin{tabular}{|c|c|c|c|c|c|c|c|c|c|c|c|c|c|c|c|c|c|}
\hline \multirow[t]{2}{*}{ NO } & \multirow{2}{*}{$\begin{array}{c}\text { Id } \\
\text { Pegawai }\end{array}$} & \multicolumn{5}{|c|}{ Variabel Internal Skill (IS) } & \multicolumn{8}{|c|}{ Variabel Technical Skill (IS) } & \multicolumn{3}{|c|}{ Variabel Utilities Skill (US) } \\
\hline & & IS1 & IS2 & IS3 & IS4 & IS5 & TS6 & TS7 & TS8 & TS9 & TS10 & TS11 & TS12 & TS13 & $\overline{\text { US14 }}$ & US15 & US16 \\
\hline 1 & TOF1 & 4 & 3 & 3 & 3 & 4 & 4 & 3 & 3 & 4 & 4 & 3 & 4 & 4 & 3 & 5 & 3 \\
\hline 2 & TOF2 & 3 & 4 & 4 & 4 & 3 & 3 & 3 & 4 & 4 & 4 & 3 & 3 & 4 & 2 & 5 & 4 \\
\hline 3 & TOF3 & 3 & 4 & 3 & 5 & 3 & 2 & 3 & 3 & 4 & 3 & 3 & 4 & 3 & 4 & 3 & 3 \\
\hline 4 & TOF4 & 3 & 3 & 4 & 4 & 3 & 3 & 2 & 3 & 4 & 3 & 4 & 3 & 3 & 3 & 3 & 3 \\
\hline 5 & TOF5 & 4 & 3 & 3 & 4 & 3 & 4 & 3 & 4 & 4 & 4 & 3 & 3 & 4 & 4 & 4 & 4 \\
\hline 6 & TOF6 & 3 & 4 & 2 & 3 & 4 & 5 & 3 & 3 & 2 & 3 & 4 & 3 & 4 & 3 & 3 & 3 \\
\hline 7 & TOF 7 & 4 & 3 & 3 & 3 & 3 & 3 & 3 & 4 & 4 & 3 & 4 & 4 & 4 & 4 & 3 & 3 \\
\hline 8 & TOF8 & 3 & 3 & 2 & 4 & 4 & 3 & 3 & 3 & 2 & 4 & 3 & 4 & 3 & 4 & 4 & 5 \\
\hline 9 & TOF9 & 4 & 4 & 3 & 3 & 3 & 2 & 4 & 3 & 3 & 3 & 3 & 4 & 4 & 3 & 3 & 4 \\
\hline 10 & TOG10 & 4 & 4 & 3 & 3 & 3 & 3 & 3 & 3 & 4 & 4 & 3 & 3 & 4 & 4 & 4 & 4 \\
\hline 11 & TOG11 & 3 & 3 & 3 & 4 & 3 & 4 & 5 & 5 & 3 & 4 & 4 & 4 & 4 & 4 & 4 & 4 \\
\hline 12 & TOG12 & 4 & 3 & 5 & 4 & 4 & 3 & 4 & 4 & 4 & 3 & 3 & 4 & 4 & 4 & 4 & 3 \\
\hline & $\begin{array}{l}\text { ai Sub } \\
\text { ria Ideal }\end{array}$ & 5 & 4 & 4 & 4 & 4 & 4 & 4 & 4 & 4 & 5 & 4 & 5 & 4 & 4 & 5 & 4 \\
\hline
\end{tabular}

\subsection{Perhitungan Nilai Gap}

Nilai gap didapatkan dari selisih nilai masing-masing sub kriteria dengan nilai sub kriteria ideal yang telah ditentukan perusahaan. Rumus untuk menentukan nilai gap adalah:

Gap = Nilai Sub Kriteria Pegawai Kontrak - Nilai Sub Kriteria Ideal 
IT Journal Research and Development

Vol.2, No.2, Maret 2018

e-ISSN: 2528-4053

Tabel 6. Nilai Sub Gap Variabel Internal Skill, Technical Skill, dan Variabel Skill

\begin{tabular}{|c|c|c|c|c|c|c|c|c|c|c|c|c|c|c|c|c|c|}
\hline \multirow[t]{2}{*}{ NO } & \multirow{2}{*}{$\begin{array}{c}\text { Id } \\
\text { Pegawai }\end{array}$} & \multicolumn{5}{|c|}{ Variabel Internal Skill (IS) } & \multicolumn{8}{|c|}{ Variabel Technical Skill (IS) } & \multicolumn{3}{|c|}{ Variabel Utilities Skill (US) } \\
\hline & & IS1 & IS2 & IS3 & IS4 & IS5 & TS6 & TS7 & TS8 & TS9 & TS10 & TS11 & TS12 & TS13 & US14 & US15 & US16 \\
\hline 1 & TOF1 & -1 & -1 & -1 & -1 & 0 & 0 & -1 & -1 & 0 & -1 & -1 & -1 & 0 & -1 & 0 & -1 \\
\hline 2 & TOF2 & -2 & 0 & 0 & 0 & -1 & -1 & -1 & 0 & 0 & -1 & -1 & -2 & 0 & -2 & 0 & 0 \\
\hline 3 & TOF3 & -2 & 0 & -1 & 1 & -1 & -2 & -1 & -1 & 0 & -2 & -1 & -1 & -1 & 0 & -2 & -1 \\
\hline 4 & TOF4 & -2 & -1 & 0 & 0 & -1 & -1 & -2 & -1 & 0 & -2 & 0 & -2 & -1 & -1 & -2 & -1 \\
\hline 5 & TOF5 & -1 & -1 & -1 & 0 & -1 & 0 & -1 & 0 & 0 & -1 & -1 & -2 & 0 & 0 & -1 & 0 \\
\hline 6 & TOF6 & -2 & 0 & -2 & -1 & 0 & 1 & -1 & -1 & -2 & -2 & 0 & -2 & 0 & -1 & -2 & -1 \\
\hline 7 & TOF 7 & -1 & -1 & -1 & -1 & -1 & -1 & -1 & 0 & 0 & -2 & 0 & -1 & 0 & 0 & -2 & -1 \\
\hline 8 & TOF8 & -2 & -1 & -2 & 0 & 0 & -1 & -1 & -1 & -2 & -1 & -1 & -1 & -1 & 0 & -1 & 1 \\
\hline 9 & TOF9 & -1 & 0 & -1 & -1 & -1 & -2 & 0 & -1 & -1 & -2 & -1 & -1 & 0 & -1 & -2 & 0 \\
\hline 10 & TOG10 & -1 & 0 & -1 & -1 & -1 & -1 & -1 & -1 & 0 & -1 & -1 & -2 & 0 & 0 & -1 & 0 \\
\hline 11 & TOG11 & -2 & -1 & -1 & 0 & -1 & 0 & 1 & 1 & -1 & -1 & 0 & -1 & 0 & 0 & -1 & 0 \\
\hline 12 & TOG12 & -1 & -1 & 1 & 0 & 0 & -1 & 0 & 0 & 0 & -2 & -1 & -1 & 0 & 0 & -1 & -1 \\
\hline
\end{tabular}

Tabel 7. Bobot Nilai Gap Variabel Internal Skill, Technical Skill, dan Variabel Skill

\begin{tabular}{|c|c|c|c|c|c|c|c|c|c|c|c|c|c|c|c|c|c|}
\hline \multirow[t]{2}{*}{ NO } & \multirow{2}{*}{$\begin{array}{c}\text { Id } \\
\text { Pegawai }\end{array}$} & \multicolumn{5}{|c|}{ Variabel Intemal Skill (IS) } & \multicolumn{8}{|c|}{ Variabel Technical Skill (IS) } & \multicolumn{3}{|c|}{ Variabel Utilities Skill (US) } \\
\hline & & IS1 & IS2 & IS3 & IS4 & IS5 & TS6 & TS7 & TS8 & TS9 & TS10 & TS11 & TS12 & TS13 & US14 & US15 & US16 \\
\hline 1 & TOF1 & 4 & 4 & 4 & 4 & 5 & 5 & 4 & 4 & 5 & 4 & 4 & 4 & 5 & 4 & 5 & 4 \\
\hline 2 & TOF2 & 3 & 5 & 5 & 5 & 4 & 4 & 4 & 5 & 5 & 4 & 4 & 3 & 5 & 3 & 5 & 5 \\
\hline 3 & TOF3 & 3 & 5 & 4 & 4.5 & 4 & 3 & 4 & 4 & 5 & 3 & 4 & 4 & 4 & 5 & 3 & 4 \\
\hline 4 & TOF4 & 3 & 4 & 5 & 5 & 4 & 4 & 3 & 4 & 5 & 3 & 5 & 3 & 4 & 4 & 3 & 4 \\
\hline 5 & TOF5 & 4 & 4 & 4 & 5 & 4 & 5 & 4 & 5 & 5 & 4 & 4 & 3 & 5 & 5 & 4 & 5 \\
\hline 6 & TOF6 & 3 & 5 & 3 & 4 & 5 & 4.5 & 4 & 4 & 3 & 3 & 5 & 3 & 5 & 4 & 3 & 4 \\
\hline 7 & TOF & 4 & 4 & 4 & 4 & 4 & 4 & 4 & 5 & 5 & 3 & 5 & 4 & 5 & 5 & 3 & 4 \\
\hline 8 & TOF8 & 3 & 4 & 3 & 5 & 5 & 4 & 4 & 4 & 3 & 4 & 4 & 4 & 4 & 5 & 4 & 4.5 \\
\hline 9 & TOF9 & 4 & 5 & 4 & 4 & 4 & 3 & 5 & 4 & 4 & 3 & 4 & 4 & 5 & 4 & 3 & 5 \\
\hline 10 & TOG10 & 4 & 5 & 4 & 4 & 4 & 4 & 4 & 4 & 5 & 4 & 4 & 3 & 5 & 5 & 4 & 5 \\
\hline \begin{tabular}{|l|}
11 \\
\end{tabular} & TOG11 & 3 & 4 & 4 & 5 & 4 & 5 & 4.5 & 4.5 & 4 & 4 & 5 & 4 & 5 & 5 & 4 & 5 \\
\hline \begin{tabular}{|l}
12 \\
\end{tabular} & TOG12 & 4 & 4 & 4.5 & 5 & 5 & 4 & 5 & 5 & 5 & 3 & 4 & 4 & 5 & 5 & 4 & 4 \\
\hline
\end{tabular}

\subsection{Pengelompokan dan Perhitungan Nilai}

\section{Core Factor dan Secondary Factor}

Tahapan selanjutnya menghitung nilai $C F$ dan $S F$ dengan terlebih dahulu mengelompokkan variabel internal skill, technical skill dan utilities skill menjadi kategori Core Factor (CF) dan Secondary Factor (SF).

a. Variabel internal Skill

Kategori $C F$ : variabel IS1, IS2, dan IS3

Kategori $S F$ : variabel IS4 dan IS5 
b. Variabel technical Skill

Kategori $C F$ : variabel TS6, TS7, TS8, dan TS9

Kategori $S F$ : variabel TS10, TS11, TS12, dan TS13

c. Variabel utilities Skill

Kategori $C F$ : variabel US14

Kategori $S F$ : variabel US15 dan US16

Untuk menghitung nilai $C F$ dan SF menggunakan rumus

Nilai $C F=$ Komponen variabel $C F / \mathrm{Jumlah}$ komponen variabel $C F$

Nilai $S F=$ Komponen variabel $S F /$ Jumlah komponen variabel $S F$.

Tabel 8. Sampel Total Nilai $C F$ dan $S F$ Variabel Internal Skill

\begin{tabular}{|c|c|c|c|c|c|c|c|c|}
\hline \multirow[t]{3}{*}{$\mathrm{NO}$} & \multirow{3}{*}{$\begin{array}{c}\text { Id } \\
\text { Peg. }\end{array}$} & \multicolumn{5}{|c|}{ Variabel Internal Skill (IS) } & \multirow{3}{*}{$\begin{array}{l}\text { Total } \\
\text { Nilai } \\
C F\end{array}$} & \multirow{3}{*}{$\begin{array}{l}\text { Total } \\
\text { Nilai } \\
\text { SF }\end{array}$} \\
\hline & & \begin{tabular}{l|l} 
IS \\
\end{tabular} & IS & IS & IS & IS & & \\
\hline & & 1 & 2 & 3 & 4 & 5 & & \\
\hline 1 & TOF1 & 4 & 4 & 4 & 4 & 5 & 4.00 & 4.50 \\
\hline 2 & TOF2 & 3 & 5 & 5 & 5 & 4 & 4.33 & 4.50 \\
\hline 3 & TOF3 & 3 & 5 & 4 & 4.5 & 4 & 4.00 & 4.25 \\
\hline 4 & TOF4 & 3 & 4 & 5 & 5 & 4 & 4.00 & 4.50 \\
\hline 5 & TOF5 & 4 & 4 & 4 & 5 & 4 & 4.00 & 4.50 \\
\hline 6 & TOF6 & 3 & 5 & 3 & 4 & 5 & 3.67 & 4.50 \\
\hline 7 & TOF7 & 4 & 4 & 4 & 4 & 4 & 4.00 & 4.00 \\
\hline 8 & TOF8 & 3 & 4 & 3 & 5 & 5 & 3.33 & 5.00 \\
\hline 9 & TOF9 & 4 & 5 & 4 & 4 & 4 & 4.33 & 4.00 \\
\hline 10 & $\begin{array}{l}\text { TOG } \\
10\end{array}$ & 4 & 5 & 4 & 4 & 4 & 4.33 & 4.00 \\
\hline 11 & $\begin{array}{l}\text { TOG } \\
11\end{array}$ & 3 & 4 & 4 & 5 & 4 & 3.67 & 4.50 \\
\hline 12 & $\begin{array}{l}\text { TOG } \\
12\end{array}$ & 4 & 4 & 4.5 & 5 & 5 & 4.17 & 5.00 \\
\hline
\end{tabular}

\subsection{Perhitungan Nilai Total Variabel Kriteria}

Jika semua nilai $C F$ dan $S F$ masing-masing variabel kriteria yaitu internal skill, technical skill, dan utilities skill telah didapatkan, maka tahapan selanjutnya adalah mencari nilai total untuk variabel kriteria internal skill, technical skill, dan utilities skill. Bobot persentase $C F$ dan $S F$ untuk masing-masing kriteria telah ditentukan sebelumnya.

a. Variabel internal skill

Persentase $C F: 60 \%$

Persentase $S F: 40 \%$

b. Variabel technical skill

Persentase $C F: 80 \%$

Persentase $S F: 20 \%$

c. Variabel utilities skill

Persentase $C F: 70 \%$

Persentase $S F: 30 \%$

Untuk menghitung nilai total variabel internal skill (IS), technical skill (TS), dan utilities skill (US) menggunakan rumus: 
Ntot IS $=(\% C F$ variabel IS $*$ Ntot CF variabel

IS $)+(\%$ SF variabel IS * Ntot SF variabel IS $)$

Ntot TS $=(\% C F$ variabel TS $*$ Ntot CF

variabel TS $)+(\% \mathrm{SF}$ variabel TS $*$ Ntot $\mathrm{SF}$ variabel TS $)$

Ntot US $=(\% C F$ variabel US $*$ Ntot CF

variabel US $)+(\%$ SF variabel US *Ntot SF variabel US $)$

\section{Tabel 9. Sampel Total Nilai $C F$ dan $S F$ Variabel Technical Skill}

\begin{tabular}{|c|c|c|c|c|}
\hline \multirow[t]{2}{*}{ NO } & \multirow[t]{2}{*}{$\begin{array}{c}\text { Id } \\
\text { Pegawai }\end{array}$} & \multicolumn{2}{|c|}{$\begin{array}{c}\text { Variabel } \\
\text { Technical Technical } \\
\text { (TS) }\end{array}$} & \multirow{2}{*}{$\begin{array}{c}\text { Nilai Total } \\
\text { Variabel Kriteria } \\
\text { Technical Skill } \\
\text { (TS) }\end{array}$} \\
\hline & & $\begin{array}{c}\text { Total Nilai } \\
C F\end{array}$ & $\begin{array}{l}\text { Total } \\
\text { Nilai } \\
\text { SF }\end{array}$ & \\
\hline 1 & TOF1 & 4.25 & 4.50 & 4.30 \\
\hline 2 & TOF2 & 4.00 & 4.50 & 4.10 \\
\hline 3 & TOF3 & 3.75 & 4.00 & 3.80 \\
\hline 4 & TOF4 & 3.75 & 4.00 & 3.80 \\
\hline 5 & TOF5 & 4.00 & 4.75 & 4.15 \\
\hline 6 & TOF6 & 4.00 & 3.88 & 3.98 \\
\hline 7 & TOF7 & 4.25 & 4.50 & 4.30 \\
\hline 8 & TOF8 & 4.00 & 3.75 & 3.95 \\
\hline 9 & TOF9 & 4.00 & 4.00 & 4.00 \\
\hline 10 & TOG10 & 4.00 & 4.25 & 4.05 \\
\hline 11 & TOG11 & 4.50 & 4.50 & 4.50 \\
\hline 12 & TOG12 & 4.00 & 4.75 & 4.15 \\
\hline
\end{tabular}

\subsection{Perhitungan Nilai Akhir}

Setelah nilai total untuk variabel kriteria internal skill, technical skill, dan utilities skill didapatkan maka tahapan selanjutnya adalah mencari nilai akhir rekrutmen. Hasil nilai akhir rekrutmen nantinya akan dijadikan sebagai penentuan rangking pegawai kontrak. Bobot persentase internal skill, technical skill, dan utilities skill untuk masingmasing kriteria telah ditentukan sebelumnya.

a. Persentase variabel kriteria internal Skill (50\%)

b. Persentase variabel kriteria technical Skill (40\%)

c. Persentase variabel kriteria utilities Skill (10\%)

Untuk menghitung nilai akhir rekrutmen menggunakan rumus:

Nilai akhir $=(\%$ bobot variabel IS $*$ Ntot variabel IS $)+(\%$ bobot variabel TS $*$ Ntot variabel IS $)+(\%$ bobot variabel US $*$ Ntot variabel US $)$

Tabel 10. Total Nilai Akhir

\begin{tabular}{|c|c|c|c|c|c|}
\hline NO & Pegawai & $\begin{array}{c}\text { Nilai Total } \\
\text { Variabel } \\
\text { Internal Skill } \\
\text { (IS) }\end{array}$ & $\begin{array}{c}\text { Nilai Total } \\
\text { Variabel } \\
\text { Technical Skill } \\
\text { (TS) }\end{array}$ & $\begin{array}{c}\text { Nilai Total } \\
\text { Variabel } \\
\text { Utilities Skill } \\
\text { (US) }\end{array}$ & $\begin{array}{c}\text { Nilai } \\
\text { Akhir } \\
\text { Rekrutmen }\end{array}$ \\
\hline 1 & TOF1 & 4.20 & 4.30 & 4.15 & 4.235 \\
\hline 2 & TOF2 & 4.40 & 4.10 & 3.60 & 4.200 \\
\hline 3 & TOF3 & 4.10 & 3.80 & 4.55 & 4.025 \\
\hline 4 & TOF4 & 4.20 & 3.80 & 3.85 & 4.005 \\
\hline 5 & TOF5 & 4.20 & 4.15 & 4.85 & 4.245 \\
\hline 6 & TOF6 & 4.00 & 3.98 & 3.85 & 3.977 \\
\hline 7 & TOF7 & 4.00 & 4.30 & 4.55 & 4.175 \\
\hline
\end{tabular}




\begin{tabular}{|l|l|l|l|l|l|}
\hline 8 & TOF8 & 4.00 & 3.95 & 4.78 & 4.058 \\
\hline 9 & TOF9 & 4.20 & 4.00 & 4.00 & 4.100 \\
\hline 10 & TOG10 & 4.20 & 4.05 & 4.85 & 4.205 \\
\hline 11 & TOG11 & 4.00 & 4.50 & 4.85 & 4.285 \\
\hline 12 & TOG12 & 4.50 & 4.15 & 4.70 & 4.380 \\
\hline
\end{tabular}

\subsection{Analisa Penentuan Rangking}

Tahapan akhir dari analisa Profile Matching dalam rekrutmen pegawai kontrak menjadi pegawai tetap adalah penentuan rangking. Empat orang dengan rangking tertinggi berpeluang besar untuk diangkat menjadi pegawai tetap. Sedangkan 8 orang selanjutnya akan dianalisa kembali apakah layak diperpanjang atau dihentikan kontrak kerjanya. Dari hasil penerapan metode Profile Matching terdapat 4 pegawai kontrak yang mendapatkan nilai tertinggi dan berpeluang besar menjadi pegawai tetap. Yaitu Id pegawai TOG 11, TOG12, TOF5 dan TOF1. Atas nama pegawai Sutarmo, Suherman, Hendrianto, dan Benny Wijaya berpeluang menjadi pegawai tetap. Pegawai yang berpeluang diperpanjang kontraknya adalah Id pegawai TOG 10, TOF2, TOF7 dan TOF9. Atas nama pegawai Suhelfi, Dalvin Ginting, Idris Purba, dan Sugeng. Sedangkan pegawai yang diputuskan kontraknya adalah Id pegawai TOF8, TOF3, TOF4 dan TOF6. Atas nama pegawai Saimun, Dedi Harmoko, Dedy Sofyan dan Himinas. Hasil perangkingan pegawai kontrak tersaji dalam tabel berikut

Tabel 11. Hasil Rangking Pegawai Kontrak

\begin{tabular}{|l|l|l|l|}
\hline NO & $\begin{array}{c}\text { Rangking } \\
\text { Nilai } \\
\text { Akhir }\end{array}$ & $\begin{array}{c}\text { Id } \\
\text { Pegawai }\end{array}$ & \multicolumn{1}{|c|}{$\begin{array}{c}\text { Nama } \\
\text { Pegawai }\end{array}$} \\
\hline 1 & 4,380 & TOG12 & Sutarmo \\
\hline 2 & 4,285 & TOG11 & Suherman \\
\hline 3 & 4,245 & TOF5 & Hendrianto \\
\hline 4 & 4,235 & TOF1 & $\begin{array}{l}\text { Benny } \\
\text { Wijaya }\end{array}$ \\
\hline 5 & 4,205 & TOG10 & Suhelfi \\
\hline 6 & 4,200 & TOF2 & $\begin{array}{l}\text { Dalvin } \\
\text { Ginting }\end{array}$ \\
\hline 7 & 4,175 & TOF7 & Idris Purba \\
\hline 8 & 4,100 & TOF9 & Sugeng \\
\hline 9 & 4,058 & TOF8 & Saimun \\
\hline 10 & 4,025 & TOF3 & $\begin{array}{l}\text { Dedi } \\
\text { Harmoko }\end{array}$ \\
\hline 11 & 4,005 & TOF4 & Dedy Sofyan \\
\hline 12 & 3,975 & TOF6 & Himinas \\
\hline
\end{tabular}

\section{KESIMPULAN DAN SARAN}

Berdasarkan hasil analisa, implementasi dan pengujian yang dilakukan, maka diambil kesimpulan sebagai berikut :

1. Permasalahan rekrutmen pegawai kontrak menjadi pegawai tetap dapat diselesaikan dengan metode Profile Matching.

2. Metode Profile Matching mampu memberikan rekomendasi penentuan status baru pegawai kontrak. 
3. Untuk memperoleh hasil rekrutmen terbaik, gunakan profil ideal tertinggi dari parameter penilaian pegawai kontrak.

Berikut ini beberapa saran yang dapat dipergunakan untuk pengembangan penelitian dalam rekrutmen pegawai kontrak menjadi pegawai tetap adalah :

1. Tambahkan metode SPK lainnya untuk melihat akurasi dan hasil perbandingan metode dalam masalah rekrutmen pegawai kontrak menjadi pegawai tetap.

2. Memperluas cakupan studi kasus, yaitu membandingkan antara perusahaan 1 dengan perusahaan lainnya.

3. Menerapkan metode Profile Matching untuk permasalahan yang lain agar terlihat hasil perbedaan hasil dan akurasi

\section{DAFTAR PUSTAKA}

[1] Indonesia (2003). “Undang-undang Ketenagakerjaan.” UU/13/2003.

[2] Joshi, Asmita dan Sodhi, J. S. (2013). "Attributes Similarities Supports Profile Matching in Social Network. International Journal of Engineering Sciences \& Emerging Technologies. 6. 368-372.

[3] Muqtadir, Asfan dan Purdianto, Irwan. (2013). Sistem Pendukung Keputusan Kenaikan Jabatan Dengan Metode Profile Matching. Seminar Nasional Aplikasi Teknologi Informasi (SNATI). 1. 48-55.

[4] Ramanjulu, M dan Babu, M. Veeresh. (2014). " Secure Profile Matching for Portable Public Networks". International Journal of Computer Applications. 117. $1-4$.

[5] Sherly, Nina. (2013). Penerapan Metode Profile Matching Dalam Sistem Pendukung Keputusan Pemberian Bonus Karyawan (Studi Kasus : PT. Sanghyang Seri Persero). Jurnal Informatika. 1. 42-47.

[6] Yarlagadda, Nageswara Rao dan Naresh, B. (2015). "Improved Privacy Preserving Profile Matching in Online Social Networks". International Journal of Science Enginerring and Advance Technology (IJSR). 03 .1112-1115. 